\title{
Concern About COVID-19 \& Support for Universal Vote by Mail
}

\author{
Matt Motta* \\ Assistant Professor \\ Department of Political Science \\ Oklahoma State University \\ matthew.motta@okstate.edu \\ Joshua M. Jansa \\ Assistant Professor \\ Department of Political Science \\ Oklahoma State University
}

With public health dangers of the novel coronavirus (COVID-19) unlikely to subside by the Fall 2020, several states are considering implementing universal vote by mail systems in advance of the General Election. Studying Americans' demand for these policies is important, as support for universal vote by mail could place pressure on policymakers to implement policies that encourage turnout, without jeopardizing public health. Drawing on insights from social and political psychology, we theorize that - while self-identified liberals are typically more likely to support vote-by-mail policies than conservatives anxiety about COVID-19's health risks could erase these differences. In a demographically representative survey of U.S. adults conducted in late April 2020 ( $\mathrm{N}=1,015)$, we find strong ideological asymmetries in vote-by-mail support among individuals who are not concerned about COVID-19's health effects. However, and consistent with our theory, we find that highly-concerned liberals and conservatives alike are highly supportive of universal vote-by-mail. The results suggest that anxiety about the pandemic may play an important role in shaping demand for universal vote-by-mail policies, across the ideological spectrum. 
The novel coronavirus (COVID-19) is a public health threat that has dramatically changed Americans' social and economic lives. The pandemic has also altered the political landscape. Several states postponed or canceled presidential primaries due to COVID-19 outbreaks.

Other states, like Wisconsin, proceeded to hold primary elections, and, in doing so, highlighted the public health risks of in-person voting during a pandemic. Lines stretched across neighborhoods as would-be voters waited in the rain to maintain social distancing. Many election officials, out of fear for their personal safety, refused to work the polls in Milwaukee; leading to the closure of 175 out of 180 precincts in the city (Nilsen \& Zhou 2020). Troublingly, at least 52 people contracted COVID-19 after participating in the election (Bauer 2020). As Wisconsin's example illustrates, COVID-19 has posed a barrier to voting that could change the size and composition of the electorate in coming elections, if voters choose not to participate.

In response to the pandemic, states are seeking safer ways to conduct elections. Several states are considering implementing universal vote-by-mail (VBM). In a universal VBM system, every eligible voter is automatically provided a mail-in ballot and secure envelope in advance of Election Day. Each voter who chooses to participate must return the ballot via U.S. mail or designated dropbox by end of business on Election Day.

Bills have been introduced in Illinois and Massachusetts to convert to universal VBM for the November 2020 general election (Rakich 2020), and the secretaries of state in Arizona and Minnesota have sought legislative approval for universal VBM (Oxford 2020; Callaghan 2020). Montana will run its June primary entirely by mail after every county in the state opted for an all-mail election (Rogers 2020), providing a glide-path to doing the same in November. In Maryland's April 28 special election for U.S. House District 7, $99 \%$ of ballots were cast by mail after every eligible voter was provided a mail-in ballot (Opilo 2020).

However, these measures have not been without partisan challenges. Perhaps most notably, President Trump argued - in advance of Wisconsin primary election - that VBM 
systems are "fraudulent in many cases." ${ }^{1}$ Other GOP elites have raised concern that VBM inherently advantages Democratic turnout. ${ }^{2}$ However, whether or not these partisan cleavages extend to the mass public - preparing to vote in a general election in a time of global pandemic - is an open question.

In this paper, we study what Americans think about universal VBM, and how concern about the health risks of COVID-19 might encourage support for VBM. Studying Americans' demand for mail-in balloting is important, as support for universal VBM could put pressure on lawmakers to implement policies that allow voters to turn out without jeopardizing their health. Public demand for VBM is particularly important, because it has become a partisan issue that tracks with the debate over other electoral reforms.

Based on previous electoral reform opinion research, we suspect that self-identified liberals are more likely to support VBM than conservatives. However, drawing on insights from social and political psychology, we theorize that anxiety about COVID-19's health risks erases these ideological differences. We find support for our theory in a representative survey of Americans fielded amid the COVID-19 crisis in late April 2020. We begin to unpack the theory and results below, beginning with a survey of how states vary on VBM procedures.

\section{State Experimentation with VBM}

Five states-Colorado, Hawaii, Oregon, Utah, and Washington- already conduct their elections entirely by mail. An additional twelve states allow localities to decide whether use VBM for certain elections. The most notable of these is California, which sent mail-in ballots to over 13 million people in 2018 (Rakich 2020). Twenty-nine states allow voters to request and cast absentee ballots for any reason (i.e. no-excuse absentee voting).

The procedures for requesting ballots vary state-to-state. Oklahoma, for example, requires voters to sign and notarize an affidavit attesting to their absence on Election Day. In Pennsylvania, though, voters may simply request a mail-in ballot online up to a

\footnotetext{
${ }^{1}$ https://www.nytimes.com/article/mail-in-voting-explained.html

${ }^{2}$ https://www.ajc.com/news/state-regional-govt-politics/pressure-mounts-for-further-delay-georgiamay-primary-election/K1wboFdcY1z7xYt7pa11MO/
} 
week prior to the election. In the remaining 16 states, voters must provide a valid excuse for why they will be absent from their precinct on Election Day in order to obtain a mail-in ballot.

Although all states allow ballots to be mailed under certain circumstances, the COVID19 crisis has led legislators to focus universal VBM for its safety and security. VBM elections can be conducted while keeping all voters and election personnel socially distanced, making it an attractive system during a pandemic. There is also scarce evidence to suggest that voting from a distance introduces more voter fraud. From 2000-2012, there were just 491 cases of mail-in voter fraud (Hasen 2020); in Oregon, there have been just a dozen cases of fraud out of millions of votes cast by mail across several elections (Weiser \& Ekeh 2020).

Additionally, most voters find the universal VBM system highly satisfactory; $81 \%$ of Oregon voters preferred VBM to in-person voting five years after Oregon implemented universal VBM (Southwell 2004). VBM systems are not only safe, secure, and satisfactory, but also can be cheaper. After initial start-up costs, VBM systems are about 35-50\% less expensive than in-person voting systems (Southwell 2004). To compensate for upfront costs, Congress is currently considering providing hundreds of millions in funding for states to convert to universal VBM (Sepulveda \& Jacobson 2020).

These benefits come without much change to overall voter turnout (e.g. Karp \& Banducci 2000). This is because the costs of voting in VBM systems are simply rearranged rather than lowered. Voters in universal VBM systems do not have to spend time locating and traveling to their polling place, but must learn a new system while reaping fewer psychological benefits of participating in an in-person community event (Southwell 2004; Arceneaux, Kousser, \& Mullin 2011; Monroe \& Sylvester 2011). As a result, VBM tends to be used by older, more educated voters who are the most likely to turnout out no matter the method of voting (Karp \& Banducci 2000; Berinsky, Burns, \& Traugott 2001; Smith \& Sylvester 2013). ${ }^{3}$

\footnotetext{
${ }^{3}$ One study does show a slight increase turnout among low propensity voters in VBM elections (Gerber, Green, \& Hill 2013), while others estimate that VBM leads to a decrease in turnout (Kousser \& Mullin 2007; Arceneaux, Kousser, \& Mullin 2011), though this can be overcome with campaigns that educate voters on how to vote by mail (Bergman \& Yates 2011).
} 
Since habitual voters are most likely to turn out, universal VBM also has little effect on the partisan composition of the electorate. Bergman \& Yates (2011) find an estimated increase of just $0.18 \%$ to $1.45 \%$ in Democratic voters over Republican voters in California counties that opted for VBM. In a recent comprehensive study of VBM elections in California, Utah, and Washington over a ten year period, Thompson et al. (2020) find no significant partisan advantage. Even when parties push for voters to cast their ballot by mail, they are not able to boost overall turnout or create a partisan advantage (Hassell 2017).

\section{The Partisan Debate over VBM}

Despite the neutral effects on turnout and partisan composition of the electorate, universal VBM has become a partisan issue. Though VBM has proven secure from voter fraud over many elections, the most prominent recent case of election fraud involved a campaign consultant collecting absentee (i.e. mail-in) ballots by hand and filling them out for the Republican candidate in the 2018 North Carolina U.S. House District 9 race.

Partisan perceptions of the prominence of voter fraud in using mail-in ballots is an important roadblock to states moving to universal VBM. Bentele \& O'Brien (2013) note that conservatives argue that restrictions on voting are "a necessary response to rampant electoral fraud perpetrated by Democrats and allied organizations" (1091). This contention is countered by liberals, who argue that restrictions are "thinly-veiled attempts by Republicans to depress turnout among constituencies deemed favorable to the Democratic Party" including minorities and young voters (Bentele \& O'Brien 2013: 1091).

Generally, the debate over electoral reforms in the states, including who qualifies for a mail-in ballot, is partisan, strategic, and racialized. Several studies establish that electorally-competitive states, states with Republican governments, and states with large

minority populations are more likely to adopt new restrictions on voters (Bentele \& O’Brien 2013; Hicks et al. 2015; Biggers \& Hanmer 2017). In particular, Florida, Georgia, Ohio, and Tennessee made it more difficult for voters to access absentee (i.e. mail-in) and early voting after the 2010 Tea Party wave (Bentele \& O'Brien 2013). 
At the national level, prominent partisan elites have expressed diverging opinions over fraud in mail-in balloting. For example, President Donald Trump claimed there was "tremendous potential for voter fraud" in VBM systems (Lillis 2020). In Congress, House Speaker Nancy Pelosi noted that universal VBM "removes obstacles to participation" and is "also healthier at this time" (Lillis 2020). The degree to which elite polarization on this issue has already translated to the mass level is an open question. Broadly, we suspect that Americans' views of universal VBM vary by ideology; with conservatives more likely to oppose and liberals more likely to support.

\section{The Neutralization Thesis}

As the above review suggests, we expect (and, later, test for) ideological disagreement about whether or not Americans support a universal vote by mail option for conducting the 2020 General Election. What is less clear from extant research, however, is whether or not a global pandemic might convince Americans to put aside their ideological commitments on this issue.

Recent advances in political psychology provide reason to suspect that Americans who are more concerned about the pandemic will be more likely to support universal vote by mail; irrespective of political ideology. People who experience anxiety, in response to impending threats, tend to be less likely to rely on their previously-held beliefs when formulating political judgments (e.g., Brader 2005; Gadarian \& Albertson 2014). According to Affective Intelligence Theory (AIT; Marcus et al., 2000), this occurs because anxiety helps people respond to impending threats by considering new information and novel courses of action that may eliminate the subject of their anxiety.

Correspondingly, threats of global pandemic have been shown to be anxiety-inducing events (e.g., Albertson \& Gadarian 2015; Keeter 2020). Consistent with AIT, people who experience anxiety in response to pandemic threats are more likely to trust information from public health experts, and are more supportive of taking collective action to combat disease spread (Albertson \& Gadarian 2015).

COVID-19 may be having similar effects on public opinion, particularly as it relates to 
the upcoming 2020 Presidential election. Although Democrats are somewhat more likely than Republicans to view the novel coronavirus as a public health threat (Van Green \& Tyson 2020), most Americans view the spread of disease as the top threat facing the country in 2020 (Poushter \& Fagan 2020). Perhaps consequently, a majority of Americans report that they would be uncomfortable voting in person on election day, and majorities of both self-identified Democrats and Republicans support states' decisions to postpone primary elections (Hartig \& Jones 2020).

Synthesizing expectations from this line of research, we expect that concern about COVID-19's health effects should attenuate the influence of political ideology on support for universal VBM. According to what we call the Neutralization Thesis, Americans who are highly concerned about COVID's health effects should be supportive of universal VBM, irrespective of ideology. Among those not concerned, however, we would expect to observe ideological polarization on the issue; such that liberals are more likely to support universal VBM than conservatives.

\section{Analytical Strategy}

We test the Neutralization Thesis by constructing a series of logistic regression models that regress support for universal VBM - as well as several alternatives to it (each in separate models) - as a function of respondents' ideological self-identification (i.e., whether they consider themselves liberals or conservatives), anxiety about the health impacts of COVID-19, and the interaction between the two; plus a series of demographic controls. If our expectations are correct, we should expect to observe a positive and statistically significant interaction between ideological conservatism and COVID-19 concern. This would indicate that conservatives' support for universal vote by mail is higher among individuals who are highly concerned about COVID-19 (compared to those who are not); thereby decreasing ideological asymmetries in support. 


\section{Data}

We test our expectations in a demographically representative online survey of $\mathrm{N}=1,015$ U.S. adults, conducted on April 26, 2020. Respondents were invited to participate in the study via Lucid Theorem's large online-opt in panel, which employed quota sampling to ensure demographic representativeness on the basis of age, race, gender, educational attainment, household income, Census region, and political party. Samples collected via Lucid have been shown to closely mirror nationally representative benchmarks on a wide range of demographic variables (Coppock \& McClellan 2018), and have been used extensively in research studying the political implications of public health attitudes (e.g., Callaghan et al., 2019; Lunz-Trujilo et al., 2020).

We account for remaining deviations between our sample and the U.S. adult population by calculating post-stratification weights that adjust for respondents' age, race, gender, educational attainment, and household income. Table S1 in the Supplementary Materials provides a comparison of our weighted and unweighted sample data to nationally representative demographic benchmarks, and suggests that our data closely resemble the U.S. adult population. We include our post-stratification syntax and population benchmark information in the Supplement as well.

\section{Measures}

Support for Universal Vote by Mail. We asked respondents to select which of four statements came closest to their views about voting in the 2020 General Election, including the possibility that eligible voters (1) should not be allowed to vote by mail, (2) should be allowed to vote by mail, but "only if they can demonstrate that they cannot vote in person on election day," (3) should be allowed to vote by mail for any reason, "but only if they request a mail ballot," and (4) should be allowed to vote by mail for any reason, and that "ballots should be mailed to the homes of all registered voters." Recall that although we analyze all scale points on this question, we are primarily concerned with the fourth option (universal vote by mail support). 
Full sample and ideological sub-sample summary statistics for this variable (and all other variables) can be found in Table 1 . Note that, consistent with the evidence reviewed earlier, we observe a substantial (13\%) decrease in support for universal vote by mail among self-identified conservatives (compared to self-identified liberals). As denoted by the non-overlapping confidence intervals - as well as an auxilliary t-test $(\mathrm{t}=\mathrm{p}<0.05$, two-tailed) - this difference is also statistically significant.

Anxiety About COVID-19 Health Effects. Additionally, we asked respondents to report whether they are "very worried," "somewhat worried," "a little worried," or "not at all worried" about the effects the novel coronavirus might have on (1) "the health of the US population as a whole," and (2) "your personal health, or the health of your loved ones." We averaged the items together into a scale $(\alpha=0.84)$, which we re-coded to range from $0-1$; such that a score of 1 denotes high levels of concern.

Symbolic Ideology. We measure respondents' symbolic ideology (Ellis \& Stimson 2012) using a standard 7-point self-placement scale ranging from "extremely liberal" to "extremely conservative;" re-scaled to range from $0-1$, such that a score of 1 denotes selfidentifying as extremely conservative.

Demographic Controls. Models also control for respondents age (binary generational cohort indicators), race (binary indicators of self-identifying as Black or Hispanic), educational attainment (a binary indicator of whether or not respondents completed college), gender (a binary indicator of whether or not respondents self-identify as women), and income (a 22-point scale, recoded to range from 0-1). Full question wording information can be found in the Supplementary Materials. 


\section{Table 1. Summary Statistics for Key Variables (Full Sample \& Ideological Sub-Groups)}

\begin{tabular}{lcccc}
\hline \hline & Full Sample & Liberals & Moderates & Conservatives \\
Oppose Mail Voting & $13 \%$ & $8 \%$ & $16 \%$ & $16 \%$ \\
& {$[11,16]$} & {$[4,12]$} & {$[11,22]$} & {$[11,21]$} \\
No Excuse Absentee & $21 \%$ & $24 \%$ & $13 \%$ & $25 \%$ \\
& {$[17,24]$} & {$[18,31]$} & {$[9,18]$} & {$[19,30]$} \\
Vote by Mail w/Restrictions & $26 \%$ & $23 \%$ & $28 \%$ & $28 \%$ \\
& {$[23,29]$} & {$[17,28]$} & {$[21,34]$} & {$[22,34]$} \\
Universal Vote by Mail & $40 \%$ & $45 \%$ & $43 \%$ & $32 \%$ \\
& {$[36,44]$} & {$[38,52]$} & {$[35,50]$} & {$[26,38]$} \\
COVID Health Concern & 0.71 & 0.76 & 0.73 & 0.63 \\
& {$[0.68,0.73]$} & {$[0.72,0.80]$} & {$[0.69,0.76]$} & {$[0.58,0.68]$} \\
\hline \hline
\end{tabular}

Note. Weighted sample and sub-sample means presented, with $95 \%$ confidence intervals in brackets. Note that non-overlapping confidence intervals suggest a statistically significant difference at the $\mathrm{p}<0.05$ level, two-tailed.

\section{Results}

Table 2 presents the results of four logistic regression models (see: Analytical Strategy) investigating the conditional effects of ideology on support by universal VBM, and three alternatives to it (see: Measures). The results provide strong evidence in support of the Neutralization Thesis. As anticipated, we find a positive and statistically significant interaction $\left(\beta=2.45, p_{i} 0.05\right.$; see Column 4$)$ between ideology and concern about the health effects of COVID-19 (bolded).

To better illustrate the substantive magnitude of these effects, Figure 1 plots the predicted probability of supporting universal VBM - expressed as $90 \%$ confidence intervals (two-tailed) - across levels of symbolic ideology, and evaluated at high (vs. low) levels of concern. The results presented in Figure 1 again provide strong support for the Neutralization Thesis.

Among individuals who express high levels of concern about the health effects of COVID-19 (in red), we find that support for universal VBM is uniformly high (approx- 
imately 50\%) for liberals, moderates, and conservatives alike. However, for individuals less concerned about COVID-19's health impact (in blue), we find deep ideological asymmetries between liberals and conservatives; as evidenced by the steep monotonic decrease in support as ideological conservatism increases.

\section{Table 2. The Conditional Effects of Ideology and COVID-19 Concern on VBM Attitudes}

\begin{tabular}{|c|c|c|c|c|}
\hline & No Mail & Absentee Only & Mail w/Restrict. & Universal Mail \\
\hline \multirow[t]{2}{*}{ Conservatism } & $3.20 *$ & 0.30 & -0.10 & $-2.66^{*}$ \\
\hline & $(1.02)$ & $(0.79)$ & $(0.63)$ & $(0.83)$ \\
\hline \multirow[t]{2}{*}{ COVID Concern } & 0.31 & 0.11 & -0.12 & -0.52 \\
\hline & $(0.94)$ & $(0.69)$ & $(0.58)$ & $(0.60)$ \\
\hline \multirow[t]{2}{*}{ Conservatism X Concern } & -2.54 & -0.43 & 0.39 & $2.45^{*}$ \\
\hline & $(1.33)$ & $(1.04)$ & $(0.86)$ & $(1.00)$ \\
\hline \multirow[t]{2}{*}{ Age $25-44$} & -0.18 & -0.31 & -0.22 & 0.60 \\
\hline & $(0.44)$ & $(0.33)$ & $(0.31)$ & $(0.34)$ \\
\hline \multirow[t]{2}{*}{ Age $44-65$} & 0.03 & $-0.76^{*}$ & 0.10 & 0.56 \\
\hline & $(0.45)$ & $(0.35)$ & $(0.30)$ & $(0.35)$ \\
\hline \multirow[t]{2}{*}{ Age $65+$} & -0.58 & -0.25 & 0.00 & 0.52 \\
\hline & $(0.50)$ & $(0.36)$ & $(0.34)$ & $(0.38)$ \\
\hline \multirow[t]{2}{*}{ Black } & 0.13 & -0.57 & 0.35 & 0.01 \\
\hline & $(0.43)$ & $(0.33)$ & $(0.30)$ & $(0.27)$ \\
\hline \multirow[t]{2}{*}{ Hispanic } & $0.86^{*}$ & 0.16 & -0.30 & -0.41 \\
\hline & $(0.36)$ & $(0.31)$ & $(0.33)$ & $(0.28)$ \\
\hline \multirow[t]{2}{*}{ College } & $-0.64^{*}$ & -0.22 & 0.21 & 0.22 \\
\hline & $(0.31)$ & $(0.26)$ & $(0.24)$ & $(0.20)$ \\
\hline \multirow[t]{2}{*}{ Female } & -0.39 & $-0.55^{*}$ & $0.39 *$ & 0.29 \\
\hline & $(0.27)$ & $(0.21)$ & $(0.19)$ & $(0.17)$ \\
\hline \multirow[t]{2}{*}{ Income } & -0.00 & -0.13 & 0.06 & 0.01 \\
\hline & $(0.52)$ & $(0.39)$ & $(0.35)$ & $(0.33)$ \\
\hline \multirow[t]{2}{*}{$\beta_{0}$} & $-2.73^{*}$ & -0.54 & $-1.34^{*}$ & -0.24 \\
\hline & $(0.82)$ & $(0.62)$ & $(0.51)$ & $(0.54)$ \\
\hline $\mathrm{N}$ & 985 & 985 & 985 & 985 \\
\hline
\end{tabular}

Note. Logistic regression parameter estimates presented with standard errors in parentheses. Data are weighted.

Interestingly, we find no evidence of a significant interaction between symbolic ideology and concern on attitudes toward absentee voting ( $\mathrm{p}=\mathrm{n}$.s. in all cases). This is consistent with the idea that alternatives to universal vote by mail may be less ideologically 
contentious than universal vote by mail; a point also borne out in Table 1 .

\section{Figure 1. Predicted Probability of Support for Universal VBM, by Ideology and COVID-19 Concern}

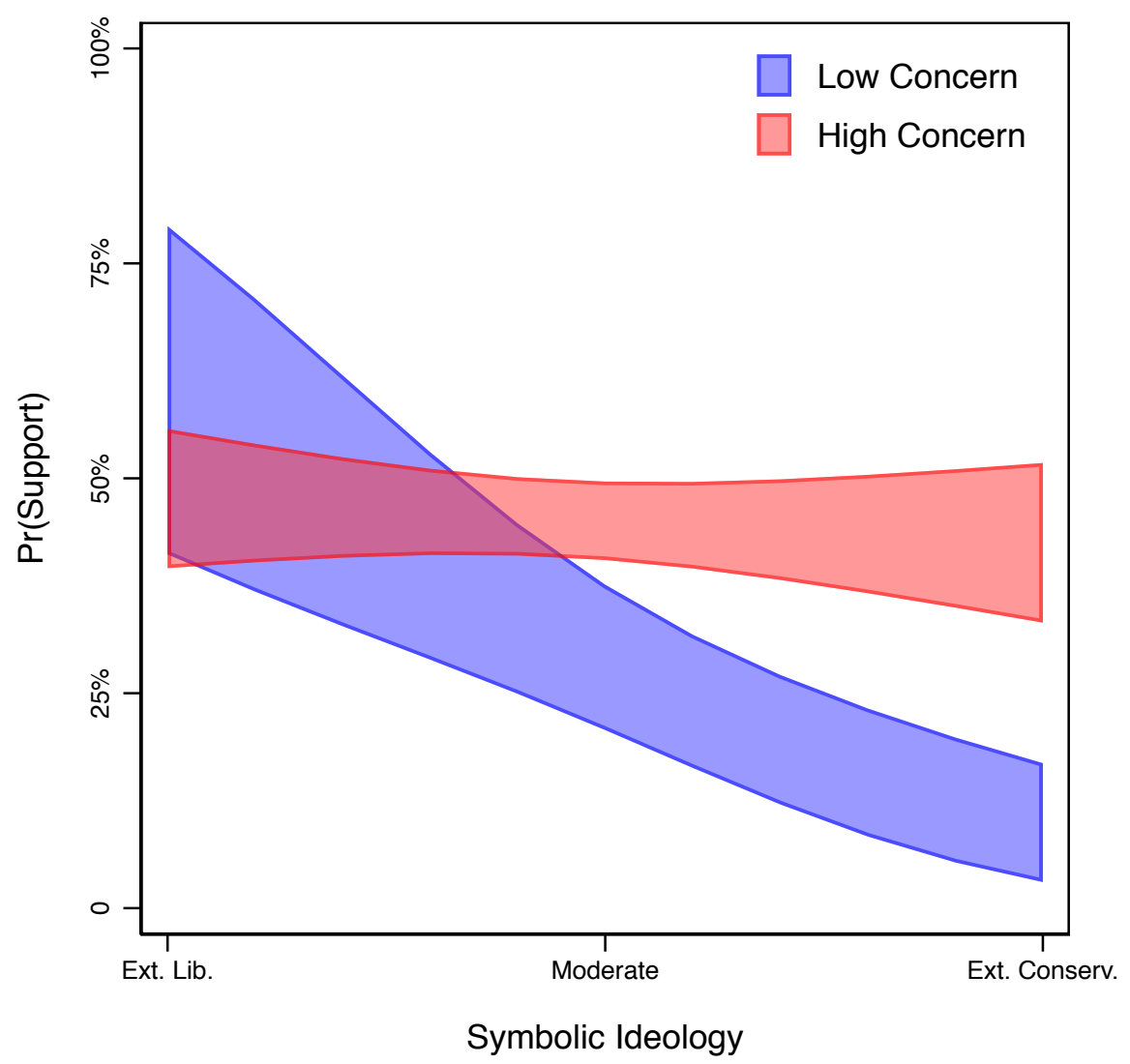

Note. Predicted probabilities are derived from the fourth model presented in Table 2. Predictions are calculated across levels of ideology, and evaluated at the lowest vs. highest $10^{t} h$ percentile scores on the COVID-19 concern scale. All other covariates are held at their sample means.

\section{Conclusion}

Our work suggests that, while public opinion toward VBM is ideologically contentious, concern about the COVID-19 pandemic may be reducing disagreement on the issue. Support for VBM from conservatives and liberals alike may provide policymakers with an incentive not only to consider using the method in times of global pandemic, but to consider expanding VBM capabilities in future elections as well. 
Of course, we caution that this work offers a snapshot of public opinion at just a single moment in time. Future research should examine the how ideological disagreement on VBM might ebb and flow both throughout and following the COVID-19 pandemic. It could be the case, for example, that as concern about COVID wanes - or becomes more ideologically contentious - people may re-consider support for these measures.

Timely, theoretically-grounded research on VBM opinion is important, given the clear implications for American democracy. Being unable to safely cast a ballot could shrink the electorate this fall and harm the health of democracy in the states. We welcome future efforts to study these important questions throughout and following this crisis.

\section{References}

Albertson, B., \& Gadarian, S. K. (2015). Anxious politics: Democratic citizenship in a threatening world. Cambridge University Press.

Arceneaux, K., Kousser, T., \& Mullin, M. (2011). Get out the vote-by-mail? A randomized field experiment testing the effect of mobilization in traditional and vote-by-mail precincts. Political Research Quarterly 65 (4): 882-894.

Bauer, S. (2020). 52 people who took part in Wisconsin's primary have COVID-19. Time. https://time.com/5829264/wisconsin-primary-coronavirus/.

Bentele, K. G. \& O'Brien E. E. (2013). Jim Crow 2.0? Why states consider and adopt restrictive voter access policies. Perspectives on Politics

Bergman, E. \& Yates, P. (2011). Changing election methods: How does mandated voteby-mail affect individual registrants. Election Law Journal, 10 (2).

Biggers, D.R. \& Hanmer, M. J. (2017). Understanding the Adoption of Voter Identification Laws in the American States. American Politics Research, 45(4): 560-588.

Brader, T. (2005). Striking a responsive chord: How political ads motivate and persuade voters by appealing to emotions. American Journal of Political Science, 49(2), 388405.

Callaghan, P. (2020). Minnesota Secretary of State Steve Simon wants to have all Minnesotans vote by mail. GOP lawmakers are having none of it. Minnesota Post. https://www.minnpost.com/state-government/2020/04/minnesota-secretary-of -state-steve-simon-wants-to-let-minnesotans-vote-by-mail-gop-lawmakers-are -having-none-of-it/

Coppock, A., \& McClellan, O. A. (2019). Validating the demographic, political, psychological, and experimental results obtained from a new source of online survey respondents. Research \& Politics, 6(1), 2053168018822174.

Gadarian, S. K., \& Albertson, B. (2014). Anxiety, immigration, and the search for information. Political Psychology, 35(2), 133-164.

Hartig, H. \& Jones, B. Most voters say postponing presidential primaries amid COVID-19 outbreak has been necessary. Pew Research Center. https://www . pewresearch.org/ 
fact-tank/2020/04/03/most-voters-say-postponing-presidential-primaries-amid -coronavirus-outbreak-has-been-necessary/

Hasen, R. L. (2020). Trump is wrong about the dangers of absentee ballots. Washington Post. urlhttps://www.washingtonpost.com/opinions/2020/04/09/trump-is-wrong-aboutdangers-absentee-ballots/

Hassell, H. J. G. (2017). Teaching voters new tricks: The effect of partisan absentee vote-by-mail get-out-the-vote efforts. Research \& Politics, 4(1): 1-6.

Hicks, W.D., McKee, S.C., Sellers, M.D., \& Smith, D.A. (2015). A Principle or a Strategy? Voter Identification Laws and Partisan Competition in the American States. Political Research Quarterly 68(1): 18-33.

Karp, J. A. \& Banducci S. A. (2000). Going postal: How all-mail elections influence turnout. Political Behavior 22: 223-239.

Keeter, S. (2020). People financially affected by COVID-19 outbreak are experiencing more psychological distress than others. Pew Research Center. https://www . pewresearch.org/fact-tank/2020/03/30/people-financially-affected-by-covid -19-outbreak-are-experiencing-more-psychological-distress-than-others/

Lillis, M. (2020). Pelosi defends push for mail-in voting: GOP 'afraid' to let people vote. The Hill. https://thehill.com/homenews/house/492116-pelosi-defends -push-for-mail-in-voting-says-gop-has-been-hijacked.

Marcus, G. E., Neuman, W. R., \& MacKuen, M. (2000). Affective intelligence and political judgment. University of Chicago Press.

Nilson, E. \& Zhou, L. How Wisconsin's election disenfranchised voters. Vox. https: //www .vox.com/2020/4/7/21212053/wisconsin-election-coronavirus-disenfranchised -voters

Opilo, E. (2020). Mfume won 7th district by smaller margin at voting centers, latest special election results show. Baltimore Sun.https://www.baltimoresun.com/ politics/bs-md-pol-7th-district-mfume-election-results-20200430-qstjuwekkngx7jw2es -story. html?fbclid=IwAR3f pwCsJc9nzHxIUSBZKOnI2ab6b0Uuf6SAZidM8_kL4uPYzeUAaF JyHNo

Oxford, A. (2020). Secretary of state wants all-mail voting across Arizona for 2020 as coronavirus spreads. Arizona Republic https://www.azcentral.com/story/news/ politics/arizona/2020/03/18/arizona-secretary-state-wants-all-mail-elections -august-november-katie-hobbs/2869153001/

Poushter, J. \& Fagan, M. Americans See Spread of Disease as Top International Threat, Along With Terrorism, Nuclear Weapons, Cyberattacks. Pew Research Center. https:// www . pewresearch.org/global/2020/04/13/americans-see-spread-of-disease-as -top-international-threat-along-with-terrorism-nuclear-weapons-cyberattacks/

Rakich, N. (2020). Few states are prepared to switch to voting by mail. That could make for a messy election. FiveThirtyEight. https://fivethirtyeight.com/features/ few-states-are-prepared-to-switch-to-voting-by-mail-that-could-make-for -a-messy-election/

Rogers, R. (2020). Montana's primary election moves to mail ballot. Billings Gazette. https://billingsgazette.com/news/state-and-regional/govt-and-politics/montanas -primary-election-moves-to-mail-ballot/article_cfb42771-38b1-5f21-aba4-c2526a644dd .html

Sepulveda, J. \& Jacobson, L. (2020). Lawmakers push for vote by mail in response to coronavirus pandemic. CNBC. https://www. cnbc.com/2020/04/06/coronavirus -election-lawmakers-push-for-vote-by-mail.html

Smith, K \& Sylvester D. E. (2013). Is it the message or the person? Lessons from a field 
experiment about who converts to permanent vote by mail. Election Law Journal 12 (3).

Southwell, P. L. (2004). Five years later: A re-assessment of Oregon's vote by mail electoral process. PS: Political Science \& Politics, 37 (1): 89-93.

Thompson, D. M., Wu, J., Yoder, J., \& Hall, A. B. (2020). The neutral partisan effects of vote-by-mail: evidence from county-level roll-outs. Democracy $\&$ Polarization Lab at Stanford University. http://www . andrewbenjaminhall.com/Thompson_et_al_VBM .pdf

Van Green, C. \& Tyson, A. 5 facts about partisan reactions to COVID-19 in the U.S. Pew Research Center. https://www. pewresearch.org/fact-tank/2020/04/02/5-facts -about-partisan-reactions-to-covid-19-in-the-u-s/

Weiser, W. R. \& Ekeh, H. (2020). The false narrative of vote-by-mail fraud. Brennan Center for Justice. https://www.brennancenter.org/our-work/analysis-opinion/ false-narrative-vote-mail-fraud

Wise, L. \& Corse A. Partisan Fight Looms Over Voting by Mail. Wall Street Journal. https://www.wsj.com/articles/partisan-fight-looms-over-voting-by-mail-11588167903 